\title{
Tongue atrophy and fasciculations in transthyretin familial amyloid neuropathy
}

An ALS mimicker

OPEN

Namita A. Goyal, MD Tahseen Mozaffar, MD

Correspondence to Dr. Goyal: namitag@uci.edu

\section{ABSTRACT}

Objective: Macroglossia is a well-known feature of amyloidosis; however, tongue atrophy and fasciculations are rarely seen and can lead to the misdiagnosis of amyotrophic lateral sclerosis (ALS).

Methods: We identified 2 unrelated patients with atypical features of tongue atrophy and fasciculations in the setting of a severe neuropathy.

Results: Both patients were confirmed to have transthyretin-related familial amyloid polyneuropathy (TTR-FAP) by genetic testing.

Conclusions: TTR-FAP should be considered as a possible mimicker of ALS when tongue atrophy and fasciculations are seen in the setting of a severely progressive polyneuropathy. Other atypical mimickers of ALS include polyglucosan body disease, hexosaminidase A deficiency, multisystem proteinopathy, and Allgrove syndrome. Neurol Genet 2015;1:e18; doi: 10.1212/NXG.0000000000000018

\section{GLOSSARY}

AAA = alacrimia, achalasia, and adrenal insufficiency; ALS = amyotrophic lateral sclerosis; FAP = familial amyloid polyneuropathy; TTR = transthyretin; TTR-FAP = transthyretin-related familial amyloid polyneuropathy.

Familial amyloid polyneuropathy (FAP) is a life-threatening disease that can be caused by a mutation in the transthyretin $(T T R)$ gene, one of the precursor proteins of amyloid. Plasma TTR is primarily synthesized by the liver and plays a role in transporting thyroid hormone and vitamin A through a complex with retinol-binding protein. There are more than 100 known mutations in the TTR gene (127 amino acids located on chromosome 18q). TTR gene mutations lead to decreased stability of the TTR tetramer, resulting in misfolded proteins that form amyloid fibrils and subsequent extracellular deposition of amyloid in several tissues (from peripheral and autonomic nerves to myocardium and intestine).

Transthyretin-related familial amyloid polyneuropathy (TTR-FAP) is an autosomal dominant progressive disorder characterized by a length-dependent sensorimotor polyneuropathy with variable autonomic dysfunction and extraneurologic multisystemic manifestations (including gastrointestinal dysfunction, cardiomyopathy, nephropathy, and ocular and leptomeningeal involvement) resulting from focal deposits of amyloid. It has a prevalence of 1.1/100,000 worldwide; however, there are geographical differences. The age at onset in endemic areas (i.e., Portugal, Sweden, Japan) is $20-40$ years, and the age at onset in nonendemic areas is greater than 50 years. Diagnosis is based on clinical presentation, amyloid deposition on tissue biopsy, and the diagnostic hallmark TTR mutation on genetic testing. Tongue enlargement (macroglossia) from amyloid infiltration of the tongue muscles is a well-known feature of the disease; however, tongue atrophy and fasciculations as manifesting signs of TTR-FAP is an atypical presentation and can be confused with motor neuron disease.

METHODS Standard protocol approvals, registrations, and patient consents. The Institutional Review Board at the University of California, Irvine, approved this retrospective study. Medical records were reviewed from patients suspected of having amyloid

From the Department of Neurology (N.A.G., T.M.) and Department of Orthopaedic Surgery (T.M.), University of California, Irvine. Funding information and disclosures are provided at the end of the article. Go to Neurology.org/ng for full disclosure forms. The Article Processing Charge was paid by the authors.

This is an open access article distributed under the terms of the Creative Commons Attribution-NonCommercial-NoDerivatives License 4.0 (CC BY-NC-ND), which permits downloading and sharing the work provided it is properly cited. The work cannot be changed in any way or used commercially. 
polyneuropathy seen in the Neuromuscular Clinic at the University of California, Irvine, between 2010 and 2015. Both patients in this study provided informed consent. The diagnosis, suspected by clinical presentation and electrodiagnostic studies, was confirmed by genetic testing, with a mutation reported in the TTR gene.

RESULTS Patient 1. A 75-year-old woman developed progressive sensory loss affecting her legs and hands accompanied by mild diffuse weakness with severe asymmetric bilateral foot drops over a period of 2 years. Additional findings on examination included tongue atrophy and fasciculations, sensory loss to all modalities in legs and hands, areflexia, and sensory ataxia. Over the subsequent 3 months, she developed dysarthria and dysphagia to liquids. Blood tests for common causes of neuropathy and neuroimaging were unrevealing. Electrodiagnostic studies showed a severe axonal sensorimotor polyneuropathy with ongoing denervation changes (fibrillation potentials) seen on needle examination of distal leg muscles. Sural nerve biopsy showed severe axonal loss; however, it was negative for amyloid (Congo red staining). Given the concern for autonomic dysfunction with new symptoms of dizziness in the setting of a severe neuropathy, TTR genetic testing was performed and revealed a heterozygous mutation in exon 4 (c.379A $>\mathrm{G}$ resulting in p.I127V substitution, legacy nomenclature p.I107V).

Patient 2. A 60-year-old man noted rapidly progressive painless weakness and sensory loss affecting both legs and arms requiring a wheelchair for mobility and accompanied by dysarthria and dysphagia over a 3-year period. He was referred for an evaluation for motor neuron disease. His examination findings included dysarthria, tongue atrophy (figure, A) with fasciculations, bilateral foot drops with severe distal-greater-than-proximal weakness, profound sensory loss, areflexia, and a wide-based ataxic gait. Blood tests and CSF studies were unremarkable. Abdominal fat pad biopsy was negative for amyloid. Electrodiagnostic studies revealed a severe axonal sensorimotor polyneuropathy with diffuse active denervation changes (fibrillation potentials) on needle examination of the arms and legs. His brother died at 61 years of age, with a reported diagnosis of amyotrophic lateral sclerosis (ALS). Given the patient's severe neuropathy and possible family history, TTR genetic testing was performed and revealed a heterozygous mutation in exon 2 (c.148G $>$ A resulting in p.V50M substitution, legacy nomenclature p.V30M). A lip biopsy showed TTR-positive deposits in the minor salivary glands (figure, B).

DISCUSSION TTR-FAP is well characterized as a progressive length-dependent sensorimotor polyneuropathy with autonomic and multiorgan systemic involvement; however, clinical heterogeneity ranges from isolated carpal tunnel syndrome to sensory neuropathy, painful neuropathy, pure dysautonomia, chronic inflammatory demyelinating polyradiculoneuropathy, and even a motor-predominant neuropathy. ${ }^{1}$ Several case reports of TTR-FAP describe a motor neuropathy with bulbar palsies (tongue atrophy and fasciculations) resembling motor neuron disease and have led to concerns of a misdiagnosis of ALS. ${ }^{1-4}$
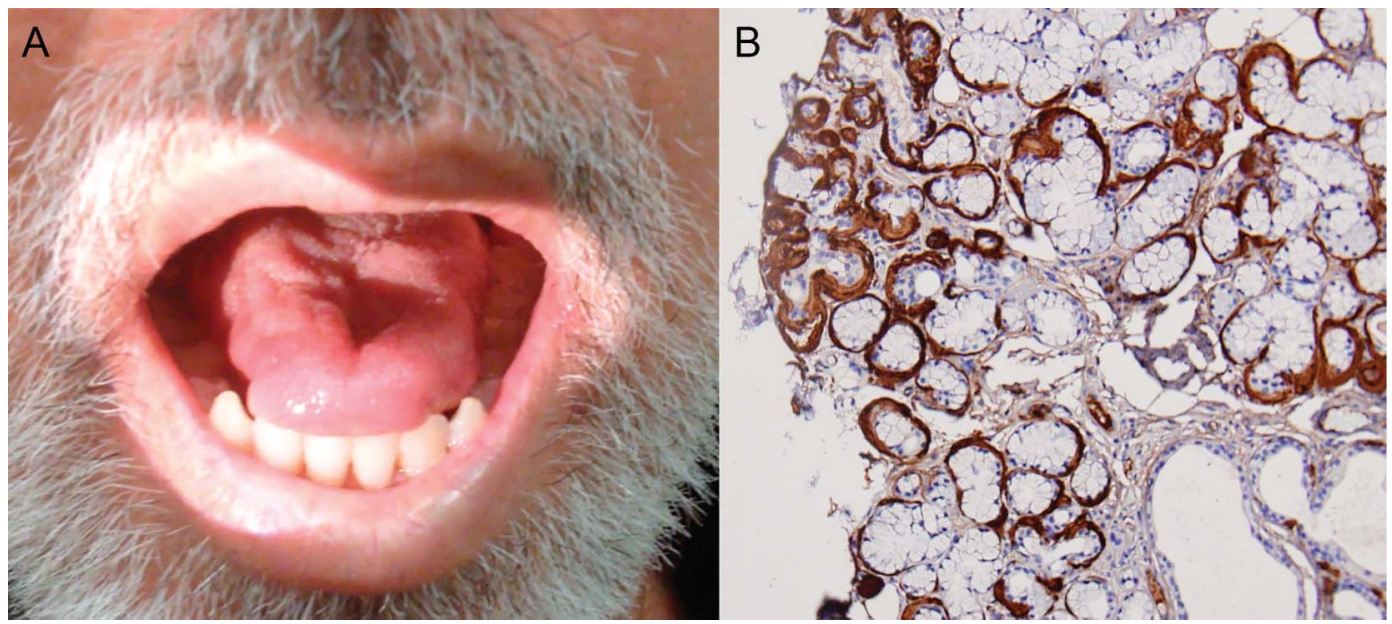

(A) Marked tongue atrophy-note the furrowing of the lateral aspects of the tongue. Marked fasciculations were noted on examination along with muscle weakness (not shown). (B) A photomicrograph of a minor salivary gland biopsy showing an immunoperoxidase staining for transthyretin (TTR) (dark brown). Diffuse deposition of TTR-positive amyloid is seen in these glands. The patient did not meet inclusion criteria for the ongoing antisense oligonucleotide trial in familial amyloid polyneuropathy secondary to markedly abnormal neuropathy impairment score. 
The majority of these rare motor-predominant neuropathy cases associated with the TTR mutation were initially suspected of having motor neuron disease, especially given the affiliated cranial nerve involvement of dysarthria, dysphagia, tongue atrophy, and fasciculations. Most of these cases were characterized by lower motor neuron features of progressive motor weakness greater than sensory involvement, atrophy, fasciculations, and areflexia with or without associated dysautonomia symptoms. Upper motor neuron features were not typically seen in these cases.

The focal manifestation of macroglossia has more commonly been described in systemic primary amyloidosis secondary to amyloid accumulation; however, tongue atrophy and fasciculations are underrecognized features in patients with TTR-FAP. We report 2 additional patients with tongue atrophy and fasciculations who have genetically confirmed TTR-FAP. In patients with severe rapidly progressive polyneuropathy and bulbar weakness, the diagnosis of FAP should be considered.

TTR-FAP thus joins a list of other rare genetic metabolic or neurodegenerative disorders that present with features of atypical ALS and should be considered in the differential diagnosis of sporadic or familial ALS. Unusual clinical characteristics that may indicate a diagnosis other than ALS may include severe polyneuropathy, dysautonomia, very slow progression, prominent lower motor neuron features (in the absence of upper motor neuron findings), severe dementia, and/or a constellation of multisystemic features in a neurologic patient. This list of atypical conditions that may mimic ALS includes adult-onset polyglucosan body disease (dementia, sensory neuropathy, and motor neuronopathy), ${ }^{5}$ late-onset hexosaminidase A deficiency (presenting as spinal muscular atrophy phenotype or ALS with upper and lower motor neuron findings; prominent cerebellar and neuropsychiatric findings help differentiate it from typical ALS), ${ }^{6}$ multisystem proteinopathy with mutations in the valosin-containing protein gene (can be associated with ALS, inclusion body myopathy, Paget disease, frontotemporal dementia, and even Parkinson disease, with phenotypic variability often in the same kindred), ${ }^{7}$ and Allgrove syndrome, with mutations in the $A A A(A L A D I N)$ gene (presenting with a sensorimotor neuropathy, autonomic disorder, and, most prominently, early-onset alacrimia, achalasia, and adrenal insufficiency [AAA] - the trio of AAA symptoms). ${ }^{8}$ ALS phenotypes have also been described with mitochondrial encephalomyopathies ${ }^{9}$ and prion diseases. ${ }^{10}$ Careful investigation of symptoms or signs that point to an alternate diagnosis, such as the ones discussed above, should be done in all patients when considering a diagnosis of ALS with atypical clinical features.

\section{AUTHOR CONTRIBUTIONS}

N.A.G. and T.M. conceived of the project and designed the study; collected and analyzed the data; and wrote and edited the manuscript.

\section{STUDY FUNDING}

No targeted funding reported.

\section{DISCLOSURE}

Dr. Goyal has received clinical research support from Alnylam and ISIS Pharmaceuticals for ongoing clinical experimental trials in FAP. Dr. Mozaffar has received clinical research support from Alnylam, ISIS Pharmaceuticals, Alexion, Amicus, Biomarin, CSL, Genzyme, GSK, Novartis, Ultragenyx, and NIH; has served on the Medical and Scientific Advisory Boards for the Myositis Association, Genzyme Corporation, Idera Pharmaceuticals, and Ultragenyx; has received travel reimbursement for advisory board meetings for Genzyme Corporation, Biomarin, and Amicus; has been a consultant for Amicus, Biomarin, Genzyme, Sarepta, and Ultragenyx; and has served on the speakers' bureau for Genzyme Corporation. Go to Neurology.org/ng for full disclosure forms.

Received May 18, 2015. Accepted in final form June 24, 2015.

\section{REFERENCES}

1. Cappellari M, Cavallaro T, Ferrarini M, et al. Variable presentations of TTR-related familial amyloid polyneuropathy in seventeen patients. J Peripher Nerv Syst 2011;16:119-129.

2. Lozeron P, Lacroix C, Theaudin M, et al. An amyotrophic lateral sclerosis-like syndrome revealing an amyloid polyneuropathy associated with a novel transthyretin mutation. Amyloid 2013;20:188-192.

3. Riboldi G, Del Bo R, Ranieri M, et al. Tyr78Phe transthyretin mutation with predominant motor neuropathy as the initial presentation. Case Rep Neurol 2011;3:62-68.

4. Salvi F, Pastorelli F, Plasmati R, Bartolomei I, Dall'Osso D, Rapezzi C. Genotypic and phenotypic correlation in an Italian population of hereditary amyloidosis TTR-related (HA-TTR): clinical and neurophysiological aids to diagnosis and some reflections on misdiagnosis. Amyloid 2012;19(suppl 1):58-60.

5. Segers K, Kadhim H, Colson C, Duttmann R, Glibert G. Adult polyglucosan body disease masquerading as "ALS with dementia of the Alzheimer type": an exceptional phenotype in a rare pathology. Alzheimer Dis Assoc Disord 2012;26:96-99.

6. Mitsumoto H, Sliman R, Schafer I, et al. Motor neuron disease and adult hexosaminidase A deficiency in two families: evidence for multisystem degeneration. Ann Neurol 1985;17:378-385.

7. Benatar M, Wuu J, Fernandez C, et al. Motor neuron involvement in multisystem proteinopathy: implications for ALS. Neurology 2013;80:1874-1880.

8. Strauss M, Koehler K, Krumbholz M, Huebner A, Zierz S, Deschauer M. Triple A syndrome mimicking ALS. Amyotroph Lateral Scler 2008;9:315-317.

9. Bannwarth S, Ait-El-Mkadem S, Chaussenot A, et al. A mitochondrial origin for frontotemporal dementia and amyotrophic lateral sclerosis through CHCHD10 involvement. Brain 2014;137:2329-2345.

10. Salazar A, Masters C, Gajdusek D, Gibbs C. Syndromes of amyotrophic lateral sclerosis and dementia: relation to transmissible Creutzfeldt-Jakob disease. Ann Neurol 1983;14:17-26. 


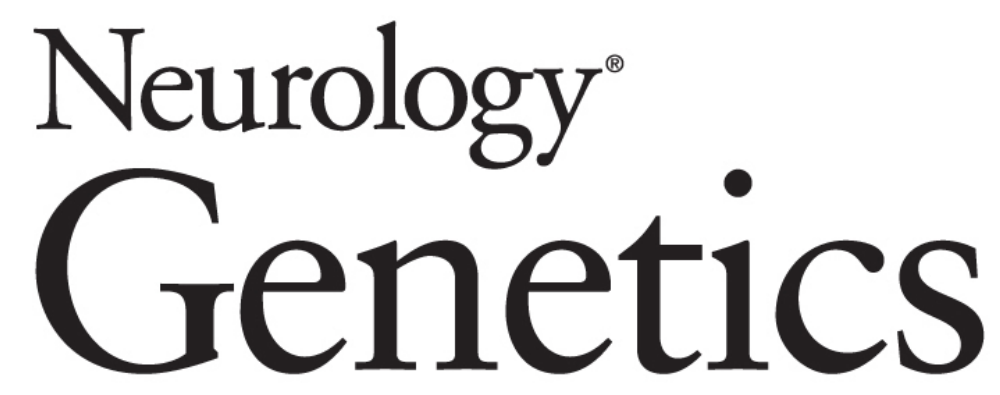

Tongue atrophy and fasciculations in transthyretin familial amyloid neuropathy: An ALS mimicker

Namita A. Goyal and Tahseen Mozaffar Neurol Genet 2015;1;

DOI 10.1212/NXG.0000000000000018

This information is current as of July 30, 2015

\section{Updated Information \&} Services

References

Citations

Subspecialty Collections

Permissions \& Licensing

Reprints including high resolution figures, can be found at: http://ng.neurology.org/content/1/2/e18.full.html

This article cites 10 articles, 0 of which you can access for free at: http://ng.neurology.org/content/1/2/e18.full.html\#\#ref-list-1

This article has been cited by 2 HighWire-hosted articles: http://ng.neurology.org/content/1/2/e18.full.html\#\#otherarticles

This article, along with others on similar topics, appears in the following collection(s):

Amyotrophic lateral sclerosis

http://ng.neurology.org//cgi/collection/amyotrophic_lateral_sclerosis_

Information about reproducing this article in parts (figures,tables) or in its entirety can be found online at:

http://ng.neurology.org/misc/about.xhtml\#permissions

Information about ordering reprints can be found online: http://ng.neurology.org/misc/addir.xhtml\#reprintsus

Neurol Genet is an official journal of the American Academy of Neurology. Published since April 2015, it is an open-access, online-only, continuous publication journal. Copyright $\odot 2015$ American Academy of Neurology. All rights reserved. Online ISSN: 2376-7839.

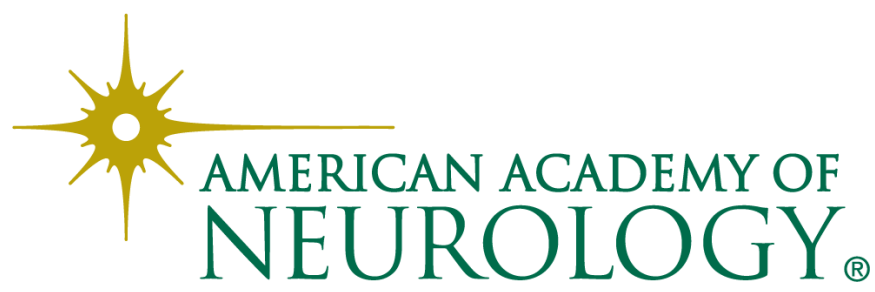

